Math. Model. Nat. Phenom.

Vol. 7, No. 5, 2012, pp. 123-132

DOI: $10.1051 / \mathrm{mmnp} / 20127509$

\title{
Host Factors in Viral Life Cycles
}

\author{
G. Pérez-Vilarón ${ }^{1}$, J. Jungfleisch ${ }^{1}$, V. Saludes ${ }^{1}$, \\ N. Scheller ${ }^{1}$, M. Giménez-Barcons ${ }^{1}, J_{\text {J Díez }}{ }^{*}$ \\ 1 Department of Experimental and Health Sciences, \\ Universitat Pompeu Fabra, 08003 Barcelona, Spain
}

\begin{abstract}
Viruses are obligate intracellular parasites that rely on the host cell for expansion. With the development of global analyses techniques like transcriptomics, proteomics and siRNA library screening of complete cellular gene sets, a large range of host cell factors have been discovered that either support or restrict virus growth. Here we summarize some of the recent findings and focus our discussion on the hepatitis $\mathrm{C}$ virus and the human immunodeficiency virus, two major pathogens that threat global health. The identification of cellular proteins affecting multiple viruses points to the existence of central regulation nodes that might be exploited for both, a quantitative description of host-virus interactions within single infected cells and the development of novel, broad-spectrum antiviral drugs.
\end{abstract}

Keywords and phrases: host factors as central regulation nodes for quantitative models of viral expansion, identification of host-virus interactions, hepatitis $\mathrm{C}$ virus, human immunodeficiency virus

Mathematics Subject Classification: 92-02, 92B05, 92C37, 92C40

\section{Introduction}

Viruses are simple infectious agents that totally depend on living cells for expansion. They are formed by a genomic nucleic acid, either DNA or RNA, and a protein shell that surrounds it. Some viruses also present an external bilipid layer that they hijack from the host when exiting the cell. Since viral genomes have a limited coding capacity, they depend on cellular functions. In fact, all fundamental cellular processes, such as for example the transcription and the translation machineries, are parasitized by viruses. It is worthy to note that, in spite of their simplicity, viruses are far of being simplistic organisms. On the contrary, they have evolved very sophisticated and elegant mechanisms to hijack the cellular functions and persist in a living cell. One challenge for the twenty-one century is precisely to unravel this intimate host-virus relationship for gaining efficient control over virus infections and to use viruses as tools for health benefit.

Viruses are extremely diverse not only in size, shape, and genetic organization but also in their replication strategies. Despite this great diversity, there are five common steps that all viruses need for expansion (Figure 1). First, they attach to the host cell through specific interactions between components in the surface of the cell and the virus. This step is critical in determining the virus host range. Second, once

\footnotetext{
${ }^{*}$ Corresponding author. E-mail: juana.diez@upf .edu
} 
attached, viruses enter into the host cell and loose many or all of the proteins contained within the virus particle in a process named uncoating. Third, now viruses are ready to amplify their genomes. In this step, they must coordinate two important events, the production of viral proteins and the replication of viral genomes. The strategies used in this step are greatly influenced by the nature of the viral genome that may be DNA or RNA, either single or double-stranded. A major difference between DNA and RNA viruses is that the latter replicate by viral polymerases that have such a high mutation rate that is unlikely that two copies of the same RNA have exactly the same nucleotide sequence. This has paramount consequences in viral evolution, pathogenesis, resistance to antiviral therapies and vaccine development (see review in this issue by Domingo and Perales). Fourth, when sufficient numbers of new genomes and proteins are produced within the host cell, they form new viruses in a process called assembly. And last, once new viruses are formed the viral progeny exit the cell, either by lysing it or by budding off into the extracellular compartment. Please note that to avoid confusion, in this review we will name the complete viral life cycle as the expansion cycle and the term replication will be used only for the specific replication step.

The expansion cycle completely depend on cellular factors. The identification of such host factors is of major importance since it provides fundamental insights into virus biology and may also suggests candidates targets for novel and efficient antiviral therapies. This review will focus in the identification and use of host factors within the cell that either promote or restrict viral expansion. In particular, we will emphasize the findings of cellular factors affecting human immunodeficiency virus type 1 (HIV-1) and hepatitis $\mathrm{C}$ virus (HCV) life cycles. Both viruses are major human pathogens that chronically infect around 30 (www.unaids.org/globalreport/Global_report.htm) and 170 (www.who.int/mediacentre/factsheets/fs164/en/index.html) million people worldwide, respectively. Currently, there are no vaccines available. A curative antiviral treatment has not yet been discovered for HIV. Nevertheless, the new therapies have successfully slowed the progression of the disease and prevent the emergence of opportunistic infections. In contrast, curative therapies do exist for HCV treatment. The current triple therapy that includes interferon, ribavirin and novel drugs that target the HCV protease eliminate the virus in $70 \%$ of infected patients. However, multiple side effects have been associated with this treatment $[34,64,73]$. Furthermore, the RNA nature of their genomes prompts the rapid generation of mutations and consequently resistance to antiviral treatments directed against viral proteins. Thus, there is an urgent need for novel therapeutic interventions. In this context, the development of drugs that target cellular proteins required for cellular expansion are of great interest since, given the genetic stability of the host, they are less likely to select virus escape mutants. In addition, as viruses from the same viral group share some fundamental properties in their replication steps, they are predicted to use common cellular pathways and thus it might be possible to develop broad-spectrum antiviral treatments.

\section{Identification of host proteins involved in viral expansion}

Due to the complexity of host genomes and host-virus interactions it is a difficult task to identify host factors that affect virus expansion. However, while our current knowledge in this field is still very limited, this situation is rapidly changing due to the implementation of recent global approaches that allow high-throughput analyses. These include genome-wide functional assays to study the effect of host factors depletion on the viral life cycle and global proteomic approaches, such as mass spectrometry and microarrays analysis, to detect direct interactions between host factors and viral proteins or genomes. Since host factors playing a critical role in viral expansion often interact with viral proteins or genomes, the combination of functional and interactome high-throughput analyses together with computational meta-analysis will result in a big step forward in the understanding of the host-virus interface. Importantly, the results obtained at a global scale would need to be later studied in an individualized way to precisely define the mechanism of action of the identified host factors. 


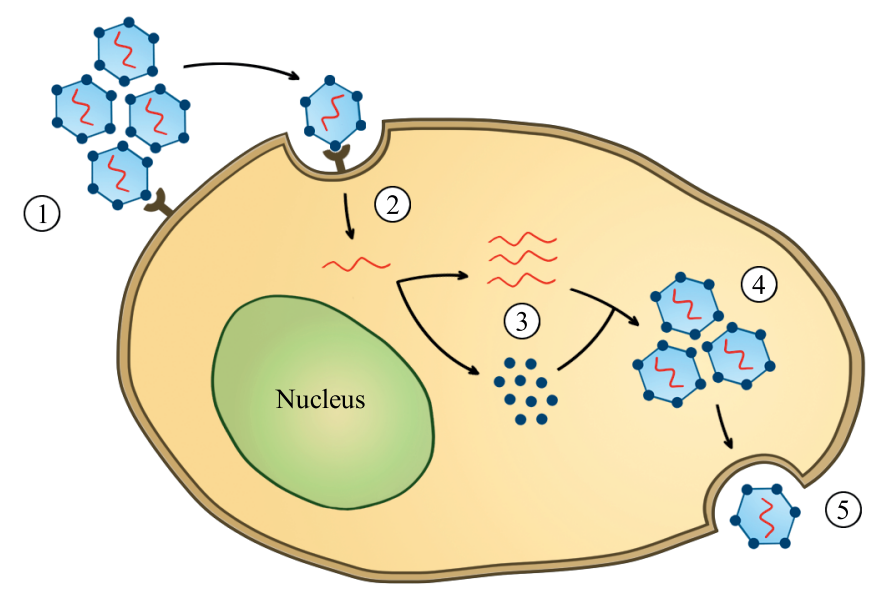

FiguRE 1. General steps in viral life cycles. All viruses infect cells through a first attachment step to the cell surface (1). Once internalized, the virus releases the viral genome into the cytoplasm (2), allowing the translation of viral proteins and the replication of the genome (3). This then generates new progeny (4) that after maturation will exit the cell to infect new cells (5).

\section{Use of yeast systems to identify host factors affecting viral expansion}

The development of systems which allow the life cycle of higher eukaryotic viruses in yeast was a milestone in virus research and enabled the use of versatile yeast tools for unraveling viral replication mechanisms. In fact, the first functional global identification of host factors affecting virus expansion was performed in the yeast Saccharomyces cerevisiae (S. cerevisiae) [42]. The use of $S$. cerevisiae as a model organism for these studies has major advantages. In contrast to the big genomes of plants and animals, yeast is built out of only 6000 genes from which over $60 \%$ have an assigned function. Furthermore, $40 \%$ of yeast genes share conserved amino acid sequences with at least one known or predicted human protein, and all the fundamental cellular processes are conserved between yeast and human cells $[10,60]$. In addition, the commercial accessibility of powerful tools and platforms allows large-scale functional analyses in yeast. These comprise (i) a gene deletion mutant collection covering around $85 \%$ of all yeast genes in which each strain contains a deletion of one non-essential gene [83], (ii) a downregulable essential-gene library that allows the study of essential genes [52], and (iii) gene libraries with fluorescent or affinity tags that facilitate interactome analyses $[24,25,31]$.

Whereas the first higher eukaryotic virus able to replicate in yeast was the plant brome mosaic virus (BMV) [35], the list rapidly expanded to other plant viruses but also to viruses that infect insects, mammals and humans $[4,57,59,65-67,88]$. The BMV-yeast system harbors additional advantages as steps of the viral life cycle can be dissected and studied separately making it possible to identify host factors affecting different steps. This is important because effects on viral progeny production could be due to alterations of each previous expansion step. Effects on the replication step of the BMV life cycle were analyzed in the 5000 strains that comprise the non-essential yeast deletion collection. From this systematic genome-wide screening, around 100 genes were found to affect BMV replication [42]. A similar study was performed for another plant virus, the tomato bushy stunt virus (TBSV). Interestingly, around 100 genes were also identified in this case [58]. Surprisingly, against all predictions only a low number of genes were found to be common in both studies. This was suggested to reflect differences in the viral replication strategies or in the experimental screening set-ups. To extend these studies to essential genes, 
additional genome-wide screenings were performed in the yeast/BMV and yeast/TBSV systems using an essential-gene library that covers $80 \%$ of the essential genes and in which each essential gene can be specifically turned off. With this approach 24 and 30 genes that affect the replication of BMV and TBSV were identified, respectively [23,37]. Taken together, these studies uncovered previously unconsidered cellular pathways, such as mRNA turnover, stress response, ribosome biosynthesis and the ubiquitin pathway of protein degradation, that either enhanced or inhibited viral replication.

Importantly, as fundamental cellular processes are highly conserved between yeast and human, host factors identified using the yeast model system might be transferred to clinically important human viruses. This principle has been already proven for the cellular LSm1, Pat1 and Dhh1 yeast proteins, referred to as LSm1, PatL1 and Rck/p54 (also named DDX6) in humans, respectively. These proteins were identified in the yeast system to be essential for BMV replication [3,14,51]. Subsequent studies in human cells demonstrated that the same set of proteins were required for the replication of the human pathogen HCV in human hepatocytes $[36,71]$. Despite this functional conservation, studies in higher eukaryotic systems are essential to validate the yeast-derived data and to explore further interactions, as not every plant or mammal protein has a functional counterpart in yeast.

\section{Identification of host factors affecting viral expansion in human cells}

RNA interference (RNAi) is widely used in human cells as a screening tool to identify cellular factors implicated in viral expansion. The RNAi pathway silences gene expression by inducing enzymatic degradation of targeted mRNAs [2]. In cell culture, RNAi is achieved by delivering small interfering RNAs (siRNAs). These are small synthetic dsRNAs, directly delivered by transfection into the cytoplasm of human cells, that act through the RNAi pathway to knockdown the complementary targeted mRNA. As a result, the corresponding encoded protein will be depleted. However, the achieved depletion is transitory due to the dilution of the intracellular siRNA concentration by cell division and degradation [11]. To increase RNAi persistence, plasmids have been designed that are introduced into the nucleus and integrate into the cell genome. These plasmids express a perfectly complementary dsRNA (short hairpin RNA, shRNA) that is subsequently processed to siRNA by cellular enzymes producing a long-term silencing effect $[79,84]$. It is important to note that silencing conditions need to be carefully optimized and controlled in order to avoid false-negative results due to low transfection efficiency, and false-positive results due to cell toxicity or non-specific binding of the siRNA/shRNA (off-target effects) [16,75]. Thus, a subsequent functional validation of the host factors showing a potential impact on the viral life cycle should be performed. Moreover, in contrast to the yeast/virus system in which the gene of interest is deleted from the yeast genome and thus its expression completely depleted, RNAi-mediated silencing in human cells does not achieve a complete depletion due to technical limitations. As a consequence, identification by siRNA analysis of key factors that are very abundant in the cell might be difficult, since it is predicted that large depletion levels would be required to make these factors limiting in the cell and thus to observe an effect on viral life cycles.

Recent advances in genomic technologies and RNAi methodologies have allowed the development of high-throughput techniques for genome-wide RNAi-based screenings. These screenings are based on the transfection of genome-wide siRNA or shRNA libraries usually containing pools of siRNAs or shRNAs, respectively. Using this technology, genome-wide RNAi-based approaches have been carried out in order to identify the complete set of cellular factors affecting the life cycle of important human pathogenic viruses, such as HIV-1 and HCV. Four major genome-wide RNAi-based screens have been published in the context of HIV-1 infection. Three of these screenings were based on the transfection of genome-wide siRNA libraries $[8,40,89]$, and led to the identification of around 800 cellular factors affecting HIV-1 infection. While some of them were described previously, the majority were novel host factors not implicated in the HIV-1 life cycle before. When the results obtained from these studies were compared later by Bushman and colleagues in a meta-analysis, the overlapping results among the identified genes after pair-wise screening comparisons was surprisingly small $(<7 \%)$ [9]. These differences were attributed to the use of diverse experimental conditions in terms of viral strains, cell lines, siRNA concentrations, siRNA libraries 
and transfection methodologies. Despite these controversies, subsequently functional analyses showed a superior overlap in terms of biological pathways. More recently, another genome-wide RNAi screening was performed based on the transfection of a shRNA library [85]. Again, although little overlap was reported on candidate genes in comparison with the previous siRNA screenings, several cellular pathways overlapped between siRNA and shRNA analyses.

Regarding HCV, two major siRNA-based genome-wide screens have been performed to study cellular factors involved in its life cycle. By transfecting siRNA pools, Tai and colleagues identified 96 host genes implicated in HCV replication [78]. An alternative approach that allowed to screen for cellular genes involved in early and late HCV expansion steps identified a total of 262 host genes, 44 of these were involved in late steps of viral infection [44]. By performing a bioinformatic meta-analysis to compare the obtained results with other screens, the authors revealed a strong statistical enrichment for several host cell pathways and complexes, as well as multiple direct interactions between the functionally defined data and comprehensive proteomic studies. Interestingly they also identified 10 host genes, such as for example DDX3, SPCS3 or Rap9p40/REBEK, that are needed by HCV and HIV-1 and thus may represent novel targets that could be exploited in instances of co-infection. In fact, a second generation of DDX3 inhibitors already demonstrates in vitro the potential of this HF as an anti-HIV target [49].

In summary, the yeast system is a fast and excellent alternative to achieve hints of putative human host factors involved in viral life cycles. However, further studies in human cells are required. In spite of the technical limitations associated with genome-wide RNAi screens, which include the possibility of false negative or positive hits, these screens are providing priceless information that in combination with global proteomics and computational meta-analyses are identifying key host proteins and pathways that promote or restrict viral life cycles. In addition, recent advances in genomics also open the option of comparing genomes among patients identifying differences that might be responsible for disease severity or progression, as well as for treatment response. One would predict that these global approaches will allow in the near future the drawing of a detailed road map of viral life cycles in infected cells.

\section{Identification of host non-coding RNAs involved in viral expansion}

All the above described studies aiming to identify host factors affecting viral life cycles were focused in the identification of cellular proteins. However, the recent discovery of non-coding RNAs (ncRNAs) uncovered an additional level of gene regulation that is essential for cell function and is predicted to have profound implications in viral life cycles. Although these implications still remain to be fully explored, very active research has been already done for one class of ncRNAs, the microRNAs (miRNAs). MiRNAs are small ncRNAs that under normal cellular conditions negatively regulate gene expression by translational repression and/or mRNA degradation [43]. However, in viral infections miRNAs can modulate viral replication and infection either negatively or positively by direct interaction with the viral genome. Clear examples are those miRNAs which have been previously described to directly influence the HCV life cycle. For example, the liver-specific miR-122 facilitates HCV replication [38] and translation [27], while others like miR-196 represses HCV expression [29]. These findings have also important clinical implications. In fact, a novel antagonist targeting the miR-122 has shown potent antiviral effects in chronic HCV-infected patients in early clinical trials [63].

All these findings were obtained analyzing a limited set of miRNAs. An ever-expanding list of highthroughput analyses are being performed to globally identify miRNAs that modulate viral life cycles. Most of the screenings are made using microarrays and aim to identify those miRNAs showing a deregulated expression after viral infection. Those miRNAs showing a potential role on viral life cycles should be

then validated by testing the effect of their depletion or overexpression in viral expansion. Several global miRNA analyses have been carried out in the setting of HIV-1 and HCV infections, both in cell culture and in vivo. From these, key studies that also include functional validations of the obtained results have identified multiple miRNAs, miRNA families and miRNA-mRNA regulatory modules that play a role in 
HIV-1 $[30,54,77,80]$ and HCV $[6,7,33,47]$ life cycles. Given the growing interest in this exciting field of research, it is expected that this list will rapidly grow and will include other species of ncRNAs that still remain to be explored.

\section{Conserved use of host factors in viral life cycles: universal host factors?}

Viruses are classified into seven groups on the basis of different strategies for storing and replicating their genomes through RNA and/or DNA intermediates. Despite major differences, three of these groups, the positive-strand RNA viruses, the double-stranded RNA viruses and the retroviruses, share two fundamental common features in their replication process. First, they all replicate their genomes through an RNA intermediate that also functions as a mRNA. Second, this mRNA is captured into protected compartments, membrane invaginations in positive-strand RNA viruses and subviral complexes in dsRNA and retrovirus, where replication takes place and competing processes such as translation are excluded [1]. The emergence of these common underlying principles suggests a common evolutionary origin and has practical implications since these shared features might provide novel targets for broad-spectrum strategies of virus control. The development of antivirals that target multiple viruses within these groups is of great clinical interest since it would allow to simplify and improve the treatment of co-infected patients, an important issue for instance in HCV (a positive-strand RNA virus) and HIV-1 (a retrovirus) co-infections. Importantly, it would also allow having a first line of defense against new emerging viruses since most of them belong to the positive-strand RNA group.

One example of cellular proteins affecting multiple viruses within these groups are the components of the cellular processing bodies (P-bodies) and stress granules (SGs). A growing number of viruses including the positive-strand RNA viruses HCV [5,6,8,21,36,41,68,70,71], poliomyelitis virus [72,76], dengue virus (DENV) [81], west nile virus [18,45]; and the retroviruses HIV-1 [2,32,48,50] and foamy virus [87] depend on P-bodies and SGs components for their expansion. P-bodies and SGs are cytoplasmatic granules highly conserved from yeast to human $[19,26]$. P-bodies contain translationally repressed mRNAs together with proteins from the mRNA decay machinery and, in humans, from the miRNA machinery as well. SGs also contain translationally repressed mRNAs, however they are stalled in the process of translation initiation, together with translation initiation factors and ribosomal subunits. Both types of granules are highly dynamic but while P-bodies are observed under normal growth conditions in higher eukaryotic cells, SGs are formed in response to conditions that result in translational repression, including different types of environmental stresses. Interestingly, many viruses have been shown to modulate the number and composition of P-bodies and SGs $[6,15,17,39,62,82]$.

Specific examples of components of these granules with a wide effect on viruses are the proteins Rck/p54 and PatL1, and the LSm1-7 heptameric complex. All these components accumulate in P-bodies and function as translation repressors on cellular mRNAs. This function seems to be hijacked by positive-strand RNA viruses and retroviruses to promote their expansion by assisting the transfer of the viral genomes from translation to the steps of replication or encapsidation $[14,51,71,87]$, processes that require translation repression. The remarkably common use of Rck/p54, PatL1 or LSm1-7 by at least one retrovirus, the foamy virus [8], and by different positive-strand RNA viruses of different kingdoms, including the human $\mathrm{HCV}[6,36,71]$ and DENV [81], the plant BMV $[14,51,55,56]$ and the phage $\mathrm{Q} \beta[22]$ point out to the existence of central regulation nodes that might be exploited for both, improving the quantitative description of host-virus interactions within single infected cells and the development of novel, broad-spectrum antiviral drugs.

\section{Conclusions and perspectives}

Host factors play a pivotal role in all aspects of viral life cycles within infected cells. With the omicstechnologies of systems biology, the last years have seen a boost of knowledge in this area. However, to fully understand virus-cell interactions, a quantitative and dynamic description of the interacting components 
with the help of mathematical models would be most valuable. Until today, most modeling attempts have concentrated on viral dynamics in infected individuals and did not consider specific viral features within single infected cells but rather assumed constant virus production rates. The rapidly increasing knowledge on host-virus cell interactions should now be considered and may substantially extend the few modeling attempts on the single cell level that have been performed $[12,13,28,46,53,69,74]$. With the inclusion of key regulatory steps in the viral life cycles that are mediated by host components under the conditions of infected cells, the new models may improve our understanding of virus-induced pathogenic processes and help to develop novel treatment regimens.

Acknowledgements. This work was supported by the grant from the Spanish Ministerio de Economía y Competitividad BFU2010-20803.

\section{References}

[1] P. Ahlquist. Parallels among positive-strand RNA viruses, reverse-transcribing viruses and double-stranded RNA viruses . Nat. Rev. Microbiol., 4 (2006), No. 5, 371-382.

[2] L. Ajamian, L. Abrahamyan, M. Milev, P.V. Ivanov, A.E. Kulozik, N.H. Gehring, A.J. Mouland. Unexpected roles for UPF1 in HIV-1 RNA metabolism and translation. RNA, 14 (2008), No. 5, 914-927.

[3] I. Alves-Rodrigues, A. Mas, J. Díez. Xenopus Xp54 and Human RCK/p54 Helicases Functionally Replace Yeast Dhh1p in Brome Mosaic Virus RNA Replication. J.Virol., 81 (2007), No. 8, 4378-4380.

[4] P.C. Angeletti, K. Kim, F.J. Fernandes, P.F. Lambert. Stable Replication of Papillomavirus Genomes in Saccharomyces cerevisiae. J. Virol., 76 (2002), No. 7, 3350-3358.

[5] Y. Ariumi, M. Kuroki, K. Abe, H. Dansako, M. Ikeda, T. Wakita, N. Kato. DDX3 DEAD-box RNA helicase is required for hepatitis $C$ virus RNA replication. J. Virol., 81 (2007), No. 24, 13922-13926.

[6] Y. Ariumi, M. Kuroki, Y. Kushima, K. Osugi, M. Hijikata, M. Maki, M. Ikeda, N. Kato. Hepatitis C virus hijacks P-body and stress granule components around lipid droplets. J. Virol., 85 (2011), No. 14, 6882-6892.

[7] S. Bandyopadhyay, R.C. Friedman, R.T. Marquez, K. Keck, B. Kong, M.S. Icardi, K.E. Brown, C.B. Burge, W.N. Schmidt, Y. Wang, A.P. McCaffrey. Hepatitis $C$ virus infection and hepatic stellate cell activation downregulate miR-29: miR-29 overexpression reduces hepatitis C viral abundance in culture. J. Infect. Dis., 203 (2011), No. 12, $1753-1762$.

[8] A.L. Brass, D.M. Dykxhoorn, Y. Benita, N. Yan, A. Engelman, R.J. Xavier, J. Lieberman, S.J. Elledge. Identification of host proteins required for HIV infection through a functional genomic screen. Science, 319 (2008), No. 5865, $921-926$.

[9] F.D. Bushman, N. Malani, J. Fernandes, I. D’Orso, G. Cagney, T.L. Diamond, H. Zhou, D.J. Hazuda, A.S. Espeseth, R. Konig, S. Bandyopadhyay, T. Ideker, S.P. Goff, N.J. Krogan, A.D. Frankel, J.A. Young, S.K. Chanda. Host cell factors in HIV replication: meta-analysis of genome-wide studies . PLoS Pathog., 5 (2009), No. 5, e1000437.

[10] J. Coller, R. Parker. Eukaryotic mRNA decapping. Annu. Rev. Biochem., 73 (2004), No. 1, 861-890.

[11] Y.L. Chiu, T.M. Rana. RNAi in human cells: basic structural and functional features of small interfering RNA . Mol. Cell, 10 (2002), No. 3, 549-561.

[12] H. Dahari, R.M. Ribeiro, C.M. Rice, A.S. Perelson. Mathematical modeling of subgenomic hepatitis $C$ virus replication in Huh-7 cells. J. Virol., 81 (2007), No. 2, 750-760.

[13] K.U. Dee, M.L. Shuler. A mathematical model of the trafficking of acid-dependent enveloped viruses: application to the binding, uptake, and nuclear accumulation of baculovirus . Biotechnol. Bioeng., 54 (1997), No. 5, 468-490.

[14] J. Diez, M. Ishikawa, M. Kaido, P. Ahlquist. Identification and characterization of a host protein required for efficient template selection in viral RNA replication. Proc. Natl .Acad. Sci. U.S.A, 97 (2000), No. 8, 3913.

[15] J.D. Dougherty, J.P. White, R.E. Lloyd. Poliovirus-mediated disruption of cytoplasmic processing bodies . J. Virol., 85 (2011), No. 1, 64-75.

[16] C.J. Echeverri, P.A. Beachy, B. Baum, M. Boutros, F. Buchholz, S.K. Chanda, J. Downward, J. Ellenberg, A.G. Fraser, N. Hacohen, W.C. Hahn, A.L. Jackson, A. Kiger, P.S. Linsley, L. Lum, Y. Ma, B. Mathey-Prevot, D.E. Root, D.M. Sabatini, J. Taipale, N. Perrimon, R. Bernards. Minimizing the risk of reporting false positives in large-scale RNAi screens . Nat. Methods, 3 (2006), No. 10, 777-779.

[17] M.M. Emara, M.A. Brinton. Interaction of TIA-1/TIAR with West Nile and dengue virus products in infected cells interferes with stress granule formation and processing body assembly. Proc. Natl. Acad. Sci. U.S.A., 104 (2007), No. 21, 9041-9046.

[18] M.M. Emara, H. Liu, W.G. Davis, M.A. Brinton. Mutation of mapped TIA-1/TIAR binding sites in the 3' terminal stem-loop of West Nile virus minus-strand RNA in an infectious clone negatively affects genomic RNA amplification . J. Virol., 82 (2008), No. 21, 10657-10670.

[19] S.L. Erickson, J. Lykke-Andersen. Cytoplasmic mRNP granules at a glance. J. Cell Sci., 124 (2011), No. Pt 3, $293-297$.

[20] A. Fire, S. Xu, M.K. Montgomery, S.A. Kostas, S.E. Driver, C.C. Mello. Potent and specific genetic interference by double-stranded RNA in Caenorhabditis elegans. Nature, 391 (1998), No. 6669, 806-811.

[21] V. Fontanes, S. Raychaudhuri, A. Dasgupta. A cell-permeable peptide inhibits hepatitis C virus replication by sequestering IRES transacting factors. Virology, 394 (2009), No. 1, 82-90. 
[22] M.T. Franze de Fernandez, L. Eoyang, J.T. August. Factor fraction required for the synthesis of bacteriophage QbetaRNA . Nature, 219 (1968), No. 154, 588.

[23] B.L. Gancarz, L. Hao, Q. He, M.A. Newton, P. Ahlquist. Systematic Identification of Novel, Essential Host Genes Affecting Bromovirus RNA Replication. PLoS ONE, 6 (2011), No. 8, e23988.

[24] D.M. Gelperin, M.A. White, M.L. Wilkinson, Y. Kon, L.A. Kung, K.J. Wise, N. Lopez-Hoyo, L. Jiang, S. Piccirillo, H. Yu, M. Gerstein, M.E. Dumont, E.M. Phizicky, M. Snyder, E.J. Grayhack. Biochemical and genetic analysis of the yeast proteome with a movable ORF collection. Genes Dev ., 19 (2005), No. 23, 2816-2826.

[25] S. Ghaemmaghami, W.-K. Huh, K. Bower, R.W. Howson, A. Belle, N. Dephoure, E.K. O'Shea, J.S. Weissman. Global analysis of protein expression in yeast. Nature, 425 (2003), No. 6959, 737-741.

[26] M. Giménez-Barcons, J. Díez. Yeast processing bodies and stress granules: self-assembly ribonucleoprotein particles . Microb. Cell Fact., 10 (2011), No. 73.

[27] J.I. Henke, D. Goergen, J. Zheng, Y. Song, C.G. Schuttler, C. Fehr, C. Junemann, M. Niepmann. microRNA-122 stimulates translation of hepatitis C virus RNA. EMBO J., 27 (2008), No. 24, 3300-3310.

[28] S.C. Hensel, J.B. Rawlings, J. Yin. Stochastic kinetic modeling of vesicular stomatitis virus intracellular growth . Bull. Math. Biol., 71 (2009), No. 7, 1671-1692.

[29] W. Hou, Q. Tian, J. Zheng, H.L. Bonkovsky. MicroRNA-196 represses Bach1 protein and hepatitis C virus gene expression in human hepatoma cells expressing hepatitis C viral proteins. Hepatology, 51 (2010), No. 5, 1494-1504.

[30] J. Huang, F. Wang, E. Argyris, K. Chen, Z. Liang, H. Tian, W. Huang, K. Squires, G. Verlinghieri, H. Zhang. Cellular microRNAs contribute to HIV-1 latency in resting primary CD4+ T lymphocytes . Nat. Med., 13 (2007), No. 10, 1241-1247.

[31] W.-K. Huh, J.V. Falvo, L.C. Gerke, A.S. Carroll, R.W. Howson, J.S. Weissman, E.K. O'Shea. Global analysis of protein localization in budding yeast. Nature, 425 (2003), No. 6959, 686-691.

[32] M. Ishaq, J. Hu, X. Wu, Q. Fu, Y. Yang, Q. Liu, D. Guo. Knockdown of cellular RNA helicase DDX3 by short hairpin RNAs suppresses HIV-1 viral replication without inducing apoptosis. Mol. Biotechnol., 39 (2008), No. 3, $231-238$.

[33] H. Ishida, T. Tatsumi, A. Hosui, T. Nawa, T. Kodama, S. Shimizu, H. Hikita, N. Hiramatsu, T. Kanto, N. Hayashi, T. Takehara. Alterations in microRNA expression profile in HCV-infected hepatoma cells: involvement of miR-491 in regulation of HCV replication via the PI3 kinase/Akt pathway. Biochem Biophys. Res. Commun., 412 (2011), No. 1, 92-97.

[34] I.M. Jacobson, J.G. McHutchison, G. Dusheiko, A.M. Di Bisceglie, K.R. Reddy, N.H. Bzowej, P. Marcellin, A.J. Muir, P. Ferenci, R. Flisiak, J. George, M. Rizzetto, D. Shouval, R. Sola, R.A. Terg, E.M. Yoshida, N. Adda, L. Bengtsson, A.J. Sankoh, T.L. Kieffer, S. George, R.S. Kauffman, S. Zeuzem. Telaprevir for previously untreated chronic hepatitis C virus infection. N. Engl. J. Med., 364 (2011), No. 25, 2405-2416.

[35] M. Janda, P. Ahlquist. RNA-dependent replication, transcription, and persistence of brome mosaic virus RNA replicons in S. cerevisiae. Cell, 72 (1993), No. 6, 961-970.

[36] R.K. Jangra, M. Yi, S.M. Lemon. DDX6 (Rck/p54) is required for efficient hepatitis C virus replication but not for internal ribosome entry site-directed translation. J. Virol., 84 (2010), No. 13, 6810-6824.

[37] Y. Jiang, E. Serviene, J. Gal, T. Panavas, P.D. Nagy. Identification of Essential Host Factors Affecting Tombusvirus RNA Replication Based on the Yeast Tet Promoters Hughes Collection. J. Virol., 80 (2006), No. 15, $7394-7404$.

[38] C.L. Jopling, M. Yi, A.M. Lancaster, S.M. Lemon, P. Sarnow. Modulation of hepatitis C virus RNA abundance by a liver-specific MicroRNA. Science, 309 (2005), No. 5740, 1577-1581.

[39] A. Khong, E. Jan. Modulation of stress granules and P bodies during dicistrovirus infection. J. Virol., 85 (2011), No. 4, 1439-1451.

[40] R. Konig, Y. Zhou, D. Elleder, T.L. Diamond, G.M. Bonamy, J.T. Irelan, C.Y. Chiang, B.P. Tu, P.D. De Jesus, C.E. Lilley, S. Seidel, A.M. Opaluch, J.S. Caldwell, M.D. Weitzman, K.L. Kuhen, S. Bandyopadhyay, T. Ideker, A.P. Orth, L.J. Miraglia, F.D. Bushman, J.A. Young, S.K. Chanda. Global analysis of host-pathogen interactions that regulate early-stage HIV-1 replication. Cell, 135 (2008), No. 1, 49-60.

[41] M. Korf, D. Jarczak, C. Beger, M.P. Manns, M. Kruger. Inhibition of hepatitis C virus translation and subgenomic replication by siRNAs directed against highly conserved HCV sequence and cellular HCV cofactors. J. Hepatol., 43 (2005), No. 2, 225-234.

[42] D.B. Kushner, B.D. Lindenbach, V.Z. Grdzelishvili, A.O. Noueiry, S.M. Paul, P. Ahlquist. Systematic, genome-wide identification of host genes affecting replication of a positive-strand RNA virus . Proc. Natl. Acad. Sci. U.S.A., 100 (2003), No. 26, 15764-15769.

[43] R.C. Lee, R.L. Feinbaum, V. Ambros. The C. elegans heterochronic gene lin-4 encodes small RNAs with antisense complementarity to lin-14. Cell, 75 (1993), No. 5, 843-854.

[44] Q. Li, A.L. Brass, A. Ng, Z. Hu, R.J. Xavier, T.J. Liang, S.J. Elledge. A genome-wide genetic screen for host factors required for hepatitis C virus propagation. Proc. Natl. Acad. Sci. U.S.A., 106 (2009), No. 38, 16410-16415.

[45] W. Li, Y. Li, N. Kedersha, P. Anderson, M. Emara, K.M. Swiderek, G.T. Moreno, M.A. Brinton. Cell Proteins TIA-1 and TIAR Interact with the $3^{\prime}$ Stem-Loop of the West Nile Virus Complementary Minus-Strand RNA and Facilitate Virus Replication. J. Virol., 76 (2002), No. 23, 11989-12000.

[46] K.I. Lim, T. Lang, V. Lam, J. Yin. Model-based design of growth-attenuated viruses . PLoS Comput. Biol., 2 (2006), No. 9, e116.

[47] X. Liu, T. Wang, T. Wakita, W. Yang. Systematic identification of microRNA and messenger RNA profiles in hepatitis $C$ virus-infected human hepatoma cells . Virology, 398 (2010), No. 1, 57-67. 
[48] M. Maeda, H. Sawa, M. Tobiume, K. Tokunaga, H. Hasegawa, T. Ichinohe, T. Sata, M. Moriyama, W.W. Hall, T. Kurata, H. Takahashi. Tristetraprolin inhibits HIV-1 production by binding to genomic RNA . Microbes Infect., 8 (2006), No. 11, 2647-2656.

[49] G. Maga, F. Falchi, M. Radi, L. Botta, G. Casaluce, M. Bernardini, H. Irannejad, F. Manetti, A. Garbelli, A. Samuele, S. Zanoli, J.A. Este, E. Gonzalez, E. Zucca, S. Paolucci, F. Baldanti, J. De Rijck, Z. Debyser, M. Botta. Toward the discovery of novel anti-HIV drugs. Second-generation inhibitors of the cellular ATPase DDX3 with improved anti-HIV activity: synthesis, structure-activity relationship analysis, cytotoxicity studies, and target validation. ChemMedChem., 6 (2011), No. 8, 1371-1389.

[50] K.L. Martin, M. Johnson, R.T. D'Aquila. APOBEC3G complexes decrease human immunodeficiency virus type 1 production. J. Virol., 85 (2011), No. 18, 9314-9326.

[51] A. Mas, I. ALves-Rodrigues, A. Noueiry, P. Ahlquist, J. Díez. Host deadenylation-dependent mRNA decapping factors are required for a key step in brome mosaic virus RNA replication. J.Virol., 80 (2006), No. 1, 246.

[52] S. Mnaimneh, A.P. Davierwala, J. Haynes, J. Moffat, W.-T. Peng, W. Zhang, X. Yang, J. Pootoolal, G. Chua, A. Lopez, M. Trochesset, D. Morse, N.J. Krogan, S.L. Hiley, Z. Li, Q. Morris, J. Grigull, N. Mitsakakis, C.J. Roberts, J.F. Greenblatt, C. Boone, C.A. Kaiser, B.J. Andrews, T.R. Hughes. Exploration of Essential Gene Functions via Titratable Promoter Alleles. Cell, 118 (2004), No. 1, 31-44.

[53] J. Nakabayashi. A compartmentalization model of hepatitis $C$ virus replication: an appropriate distribution of $H C V$ RNA for the effective replication. J. Theor. Biol., 300 (2012), No. 110-117.

[54] R. Nathans, C.Y. Chu, A.K. Serquina, C.C. Lu, H. Cao, T.M. Rana. Cellular microRNA and P bodies modulate host-HIV-1 interactions. Mol. Cell, 34 (2009), No. 6, 696-709.

[55] A.O. Noueiry, J. Chen, P. Ahlquist. A mutant allele of essential, general translation initiation factor DED1 selectively inhibits translation of a viral mRNA . Proc. Natl. Acad. Sci. U.S.A., 97 (2000), No. 24, 12985-12990.

[56] A.O. Noueiry, J. Díez, S.P. Falk, J. Chen, P. Ahlquist. Yeast Lsm1p- ₹p/Pat1p Deadenylation-Dependent mRNADecapping Factors Are Required for Brome Mosaic Virus Genomic RNA Translation. Mol. Cell. Biol., 23 (2003), No. 12, 4094-4106.

[57] T. Panavas, P.D. Nagy. Yeast as a model host to study replication and recombination of defective interfering RNA of Tomato bushy stunt virus. Virology, 314 (2003), No. 1, 315-325.

[58] T. Panavas, E. Serviene, J. Brasher, P.D. Nagy. Yeast genome-wide screen reveals dissimilar sets of host genes affecting replication of RNA viruses. Proc. Natl. Acad. Sci. U.S.A., 102 (2005), No. 20, 7326-7331.

[59] V. Pantaleo, L. Rubino, M. Russo. Replication of Carnation Italian Ringspot Virus Defective Interfering RNA in Saccharomyces cerevisiae. J. Virol., 77 (2003), No. 3, 2116-2123.

[60] A.B. Parsons, R. Geyer, T.R. Hughes, C. Boone. Yeast genomics and proteomics in drug discovery and target validation Prog. Cell Cycle Res., 5 (2003), No. 159-166.

[61] X. Peng, Y. Li, K.A. Walters, E.R. Rosenzweig, S.L. Lederer, L.D. Aicher, S. Proll, M.G. Katze. Computational identification of hepatitis $C$ virus associated microR $N A-m R N A$ regulatory modules in human livers. BMC Genomics, 10 (2009), No. 373.

[62] G. Pérez-Vilaró, N. Scheller, V. Saludes, J. Díez. HCV infection alters P-body composition but is independent of P-body granules . J. Virol., 86 (2012), No. 16, 8740-8749.

[63] R. Persson, M. Hodges, B.D. King, A. Chen, K. Zeh, A.A. Levine. Pharmacokinetics of Miravirsen, a miR-122 inhibitor, predict the prolonged viral load reduction in treatment naive genotype $1 \mathrm{HCV}$ infected patients . J. Hepatol., 56 (2012), Suppl. 2, S477.

[64] F. Poordad, J. McCone, Jr., B.R. Bacon, S. Bruno, M.P. Manns, M.S. Sulkowski, I.M. Jacobson, K.R. Reddy, Z.D. Goodman, N. Boparai, M.J. DiNubile, V. Sniukiene, C.A. Brass, J.K. Albrecht, J.P. Bronowicki. Boceprevir for untreated chronic HCV genotype 1 infection. N. Engl. J. Med., 364 (2011), No. 13, 1195-1206.

[65] B.D. Price, L.D. Eckerle, L.A. Ball, K.L. Johnson. Nodamura virus RNA replication in Saccharomyces cerevisiae: heterologous gene expression allows replication-dependent colony formation. J. Virol., 79 (2005), No. 1, 495-502.

[66] B.D. Price, R.R. Rueckert, P. Ahlouist. Complete replication of an animal virus and maintenance of expression vectors derived from it in Saccharomyces cerevisiae. Proc. Natl. Acad. Sci. U.S.A., 93 (1996), No. 18, 9465-9470.

[67] V. Raghavan, P.S. Malik, N.R. Choudhury, S.K. Mukherjee. The DNA-A Component of a Plant Geminivirus (Indian Mung Bean Yellow Mosaic Virus) Replicates in Budding Yeast Cells . J. Virol., 78 (2004), No. 5, 2405-2413.

[68] G. Randall, M. Panis, J.D. Cooper, T.L. Tellinghuisen, K.E. Sukhodolets, S. Pfeffer, M. Landthaler, P. Landgraf, S. Kan, B.D. Lindenbach, M. Chien, D.B. Weir, J.J. Russo, J. Ju, M.J. Brownstein, R. Sheridan, C. Sander, M. Zavolan, T. Tuschl, C.M. Rice. Cellular cofactors affecting hepatitis C virus infection and replication. Proc. Natl. Acad. Sci. U.S.A., 104 (2007), No. 31, 12884-12889.

[69] B. Reddy, J. Yin. Quantitative intracellular kinetics of HIV type 1. AIDS Res Hum. Retroviruses, 15 (1999), No. 3, 273-283.

[70] A. Rivas-Aravena, P. Ramdohr, M. Vallejos, F. Valiente-Echeverria, V. Dormoy-Raclet, F. Rodriguez, K. Pino, C. Holzmann, J.P. Huidobro-Toro, I.E. Gallouzi, M. Lopez-Lastra. The Elav-like protein HuR exerts translational control of viral internal ribosome entry sites. Virology, 392 (2009), No. 2, 178-185.

[71] N. Scheller, L.B. Mina, R.P. Galao, A. Chari, M. Giménez-Barcons, A. Noueiry, U. Fischer, A. Meyerhans, J. Díez. Translation and replication of hepatitis $C$ virus genomic $R N A$ depends on ancient cellular proteins that control mRNA fates . Proc. Natl. Acad. Sci. U.S.A., 106 (2009), No. 32, 13517-13522.

[72] P. Sean, J.H. Nguyen, B.L. Semler. Altered interactions between stem-loop IV within the 5 ' noncoding region of coxsackievirus RNA and poly $(r C)$ binding protein 2: effects on IRES-mediated translation and viral infectivity. Virology, 389 (2009), No. 1-2, 45-58. 
[73] K.E. Sherman, S.L. Flamm, N.H. Afdhal, D.R. Nelson, M.S. Sulkowski, G.T. Everson, M.W. Fried, M. Adler, H.W. Reesink, M. Martin, A.J. Sankoh, N. Adda, R.S. Kauffman, S. George, C.I. Wright, F. Poordad. Response-guided telaprevir combination treatment for hepatitis C virus infection. N. Engl. J. Med., 365 (2011), No. 11, 1014-1024.

[74] Y. Sidorenko, U. Reichl. Structured model of influenza virus replication in MDCK cells . Biotechnol. Bioeng., 88 (2004), No. 1, 1-14.

[75] M. Sioud. Promises and challenges in developing RNAi as a research tool and therapy. Methods Mol. Biol., 703 (2011), No. 173-187.

[76] A. Spear, N. Sharma, J.B. Flanegan. Protein-RNA tethering: the role of poly $(C)$ binding protein 2 in poliovirus RNA replication. Virology, 374 (2008), No. 2, 280-291.

[77] G. Sun, H. Li, X. Wu, M. Covarrubias, L. Scherer, K. Meinking, B. Luk, P. Chomchan, J. Alluin, A.F. Gombart, J.J. Rossi. Interplay between HIV-1 infection and host microRNAs . Nucleic Acids Res., 40 (2012), No. 5, $2181-2196$.

[78] A.W. Tai, Y. Benita, L.F. Peng, S.S. Kim, N. Sakamoto, R.J. Xavier, R.T. Chung. A functional genomic screen identifies cellular cofactors of hepatitis C virus replication. Cell Host Microbe, 5 (2009), No. 3, $298-307$.

[79] G. Tiscornia, O. Singer, M. Ikawa, I.M. Verma. A general method for gene knockdown in mice by using lentiviral vectors expressing small interfering RNA. Proc. Natl. Acad. Sci. U.S.A., 100 (2003), No. 4, 1844-1848.

[80] R. Triboulet, B. Mari, Y.L. Lin, C. Chable-Bessia, Y. Bennasser, K. Lebrigand, B. Cardinaud, T. Maurin, P. Barbry, V. Baillat, J. Reynes, P. Corbeau, K.T. Jeang, M. Benkirane. Suppression of microRNA-silencing pathway by HIV-1 during virus replication. Science, 315 (2007), No. 5818, 1579-1582.

[81] A.M. Ward, K. Bidet, A. Yinglin, S.G. Ler, K. Hogue, W. Blackstock, J. Gunaratne, M.A. Garcia-Blanco. Quantitative mass spectrometry of DENV-2 RNA-interacting proteins reveals that the DEAD-box RNA helicase DDX6 binds the DB1 and DB2 3' UTR structures . RNA Biol., 8 (2011), No. 6, 1173-1186.

[82] J.P. White, R.E. Lloyd. Regulation of stress granules in virus systems . Trends Microbiol., 20 (2012), No. 4, $175-183$.

[83] E.A. Winzeler, D.D. Shoemaker, A. Astromoff, H. Liang, K. Anderson, B. Andre, R. Bangham, R. Benito, J.D. Boeke, H. Bussey, A.M. Chu, C. Connelly, K. Davis, F. Dietrich, S.W. Dow, M. El Bakkoury, F. Foury, S.H. Friend, E. Gentalen, G. Giaever, J.H. Hegemann, T. Jones, M. Laub, H. Liao, N. Liebundguth, D.J. Lockhart, A. Lucau-Danila, M. Lussier, N. M'Rabet, P. Menard, M. Mittmann, C. Pai, C. Rebischung, J.L. Revuelta, L. Riles, C.J. Roberts, P. Ross-MacDonald, B. Scherens, M. Snyder, S. Sookhai-Mahadeo, R.K. Storms, S. V?ronneau, M. Voet, G. Volckaert, T.R. Ward, R. Wysocki, G.S. Yen, K. Yu, K. Zimmermann, P. Philippsen, M. Johnston, R.W. Davis. Functional Characterization of the S. cerevisiae Genome by Gene Deletion and Parallel Analysis . Science, 285 (1999), No. 5429, 901-906.

[84] H. Xia, Q. Mao, H.L. Paulson, B.L. Davidson. siRNA-mediated gene silencing in vitro and in vivo . Nat. Biotechnol., 20 (2002), No. 10, 1006-1010.

[85] M.L. Yeung, L. Houzet, V.S. Yedavalli, K.T. Jeang. A genome-wide short hairpin RNA screening of jurkat T-cells for human proteins contributing to productive HIV-1 replication. J. Biol. Chem., 284 (2009), No. 29, $19463-19473$.

[86] Z. Yi, C. Fang, T. Pan, J. Wang, P. Yang, Z. Yuan. Subproteomic study of hepatitis C virus replicon reveals RasGTPase-activating protein binding protein 1 as potential HCV RC component. Biochem. Biophys. Res. Commun., 350 (2006), No. 1, 174-178.

[87] S.F. Yu, P. Lujan, D.L. Jackson, M. Emerman, M.L. Linial. The DEAD-box RNA helicase DDX6 is required for efficient encapsidation of a retroviral genome. PLoS Pathog., 7 (2011), No. 10, e1002303.

[88] K.-N. Zhao, I.H. Frazer. Replication of Bovine Papillomavirus Type 1 (BPV-1) DNA in Saccharomyces cerevisiae following Infection with BPV-1 Virions. J. Virol., 76 (2002), No. 7, 3359-3364.

[89] H. Zhou, M. Xu, Q. Huang, A.T. Gates, X.D. Zhang, J.C. Castle, E. Stec, M. Ferrer, B. Strulovici, D.J. Hazuda, A.S. Espeseth. Genome-scale RNAi screen for host factors required for HIV replication. Cell Host Microbe, 4 (2008), No. $5,495-504$ 